\title{
IRI-2001 model predictions compared with ionospheric data observed at Brazilian low latitude stations
}

\author{
F. Bertoni ${ }^{1}$, Y. Sahai ${ }^{2}$, W. L. C. Lima ${ }^{1}$, P. R. Fagundes ${ }^{2}$, V. G. Pillat ${ }^{2}$, F. Becker-Guedes ${ }^{2}$, and J. R. Abalde \\ ${ }^{1}$ Centro Universitário Luterano de Palmas (CEULP/ULBRA), Palmas, Tocantins, Brazil \\ ${ }^{2}$ Universidade do Vale do Paraíba (UNIVAP), São José dos Campos, São Paulo, Brazil
}

Received: 31 March 2006 - Revised: 4 July 2006 - Accepted: 19 July 2006 - Published: 13 September 2006

\begin{abstract}
In this work, the F-region critical frequency (foF2) and peak height (hmF2) measured by digital ionosondes at two Brazilian low-latitude stations, namely Palmas $\left(10.17^{\circ} \mathrm{S}, 48.20^{\circ} \mathrm{W}\right.$, dip $\left.-10.80^{\circ}\right)$ and São José dos Campos $\left(23.20^{\circ} \mathrm{S}, 45.86^{\circ} \mathrm{W}\right.$, dip $\left.-38.41^{\circ}\right)$, are compared with the IRI-2001 model predictions. The comparison at the latter station shows quite a reasonable agreement for both parameters. The former station exhibits a better agreement for $\mathrm{hmF} 2$ than for foF2. In general, the model generates good results, although some improvements are still necessary to implement in order to obtain better simulations for equatorial ionospheric regions.
\end{abstract}

Keywords. Ionosphere (Equatorial ionosphere; Modeling and forecasting; Instruments and techniques)

\section{Introduction}

A large number of papers deal with the comparisons between observed ionospheric data and the International Reference Ionosphere (IRI) model predictions (e.g. Abdu et al., 1996; Batista et al., 1996; Souza et al., 2003; Sethi et al., 2004; Batista and Abdu, 2004). It is well known that IRI is an empirical ionospheric model based on experimental observations of the ionospheric plasma either by ground or in-situ measurements. The main purpose of IRI is to provide reliable ionospheric densities, composition and temperatures (e.g. Bilitza, 2001; Bilitza et al., 1979). Two different computer programs have been used as sub-routines by IRI: one is called the CCIR model, which was developed by Comité Consultatif International des Radiocommunications (CCIR, 1967 and 1991); and the other is the URSI model, which was developed by Union Radio-Scientifique Internationale (URSI) (Rush et al., 1983, 1984, 1989; Fox and McNa-

Correspondence to: F. Bertoni

(bertoni@ulbra-to.br) mara, 1988). These two models (CCIR and URSI) use all the compiled observational data (foF2, hmF2 and M(3000)F2), and generate numerical maps (or numerical coefficient maps) through the application of Fourier and Legendre series, providing values for the variation of the ionospheric parameters for IRI. A joint task group of URSI and COSPAR regularly update their numerical maps and coefficients as new data input is processed and added to the database and consequently a newer version of the IRI model, containing updated CCIR and URSI sub-routines, is released approximately every five years. As a result of this update and because we have compared foF 2 and $\mathrm{hmF} 2$ ionospheric parameters in this paper, and not the ionospheric plasma densities, composition or temperatures, we have adopted the nomenclature CCIR and URSI IRI-2001, in order to refer to these two different models. All comparative studies give feedback for new improvements of CCIR and URSI IRI models.

Data recorded by two digital ionosondes (Canadian Advanced Digital Ionosondes (CADIs) (Grant et al., 1995) located at low-latitude Brazilian stations, namely Palmas $\left(10.17^{\circ} \mathrm{S}, 48.20^{\circ} \mathrm{W}\right.$, dip $-10.80^{\circ}$, hereafter called PAL $)$ and São José dos Campos $\left(23.20^{\circ} \mathrm{S}, 45.86^{\circ} \mathrm{W}\right.$, dip $-38.41^{\circ}$, hereafter called SJC), were analyzed and compared with IRI2001 predictions. PAL is located near the equatorial ionization anomaly (EIA) trough, while SJC is under its crest. Therefore, the studies presented in this work are interesting as they provide a comparison of the seasonal patterns of the ionospheric parameters obtained in the ionospheric anomaly region in the Brazilian sector and IRI-2001 model predictions.

\section{Results and discussions}

We have considered the observations taken in the months of July 2003, October 2003, January 2004 and April 2004 as representatives of the Southern Hemisphere winter, spring,

Published by Copernicus GmbH on behalf of the European Geosciences Union. 
Table 1. Selected geomagnetically quiet days for different months with solar and geophysical indices.

\begin{tabular}{|c|c|c|c|c|c|c|c|}
\hline \multicolumn{8}{|c|}{ Month Year } \\
\hline July 2003 & & Day & 8 & 9 & 10 & 21 & 22 \\
\hline $\mathrm{IG}_{12}$ & $\mathrm{Rz}_{12}$ & F10.7 & 135.7 & 130.7 & 126.9 & 160.7 & 157.4 \\
\hline 74 & 61.8 & & & & & & \\
\hline Oct 2003 & & Day & 2 & 4 & 5 & 8 & 23 \\
\hline $\mathrm{IG}_{12}$ & $\mathrm{Rz}_{12}$ & F10.7 & 125.0 & 119.0 & 109.6 & 113.1 & 181.3 \\
\hline 63.1 & 58.2 & & & & & & \\
\hline Jan 2004 & & Day & 8 & 12 & 14 & 29 & 31 \\
\hline $\mathrm{IG}_{12}$ & $\mathrm{Rz}_{12}$ & F10.7 & 116.1 & 114.4 & 117.1 & 84.8 & 91.6 \\
\hline 57.4 & 52 & & & & & & \\
\hline April 2004 & & Day & 1 & 2 & 20 & 22 & 29 \\
\hline $\mathrm{IG}_{12}$ & $\mathrm{Rz}_{12}$ & F10.7 & 112.6 & 108.1 & 111.8 & 118.4 & 89.8 \\
\hline 54.1 & 45.5 & & & & & & \\
\hline
\end{tabular}

Sources: ftp://ftp.ngdc.noaa.gov/STP/SOLAR_DATA/SOLAR_RADIO/FLUX/DAILYPLT.ADJ,

ftp://nssdcftp.gsfc.nasa.gov/models/ionospheric/iri/iri2001/fortran_code/

summer and autumn seasons, respectively. Five magnetically quiet days of each of those months were selected, according to the availability of the observational data at the two stations. Ionograms were recorded every $5 \mathrm{~min}$ on a routine basis. Ionospheric F-region parameters such as the critical frequency (foF2), minimum virtual height $\left(h^{\prime} F\right)$, true height of the electron density peak (hmF2), and virtual height at a frequency of $83.4 \%$ of foF 2 (hpF2 - an estimate of the true height density peak) were scaled and averaged for the 5-selected days during each month (representing a particular season). The scaling of ionograms used the software developed at Universidade do Vale do Paraíba (UNIVAP) called the UNIVAP Digital Ionosonde Data Analysis (UDIDA) (Fagundes et al., 2005). The digital ionospheric data registered by the CADIs are displayed on a PC monitor screen for scaling of ionograms. The measurement accuracies using this system are about $\pm 3 \mathrm{~km}$ for the virtual height determination and about $\pm 0.1 \mathrm{MHz}$ for the F-region critical frequency (foF2). However, sometimes the ionogram trace needs extrapolation to determine the virtual height and/or the critical frequency. In this case, the measurement accuracies are less and are of the order of $\pm 6 \mathrm{~km}$ for the virtual height and $\pm 1.0 \mathrm{MHz}$ for the critical frequency.

Solar activity was high to moderate, on the selected days. Table 1 shows solar flux and also the 12-month smoothed values of the Ionospheric Global $\left(\mathrm{IG}_{12}\right)$ and the sunspot number $\left(\mathrm{Rz}_{12}\right)$ indices.

Figure 1a shows the diurnal variations for the different seasons of the observed and IRI-2001 predicted (using both the URSI and CCIR coefficients) foF2 values. The observed and modeled results for PAL are shown on the left hand side, while SJC is on the right-hand side. The observed foF 2 mean value curves are shown with standard deviation bars. The method of pure visualization of different curves plotted in a figure is sometimes not enough to make a good analysis. So, we applied a criterion called "relative deviation module mean" (rdmm), used by Bertoni (2004), in order to quantify the agreement/disagreement between the observed and modeled curves, and which is calculated according to the following expression:

$$
\langle\Delta\rangle=\frac{1}{N} \sum_{i=1}^{N} \frac{\left|x_{i}^{o}-x_{i}^{m}\right|}{x_{i}^{o}},
$$

where $x_{i}^{o}$ and $x_{i}^{m}$ represent observed and modeled values, respectively, and $N$ is the number of terms. This is a useful method to systemize the analysis of the results. We establish two range times for each of the means: 09:00-21:00 UT (daytime; LT=UT-3 h) and 21:00-09:00 UT (nighttime; $\mathrm{LT}=\mathrm{UT}-3 \mathrm{~h}$ ). In this way, we can have a good estimate of the model performance for the day and night periods. We define $\left\langle\Delta_{C}\right\rangle$ and $\left\langle\Delta_{U}\right\rangle$ for CCIR and URSI numerical maps, respectively, representing the total $\mathrm{rdmm}$ for that month, as well as, $\left\langle\Delta_{C d}\right\rangle,\left\langle\Delta_{C n}\right\rangle,\left\langle\Delta_{U d}\right\rangle$, and $\left\langle\Delta_{U n}\right\rangle$ for CCIR/URSI daytime/nighttime periods. According to Bertoni (2004), modeling generally exhibits a reasonable to good agreement when, besides visually, the rdmm reaches values equal to or less than 0.06 , and a reasonable to poor agreement for higher values.

From Fig. 1a, left panel, for the location of PAL, IRI-2001 predictions of foF2 generally exhibit a reasonable to poor agreement. The averaged rdmms of all of the means have values higher than 0.06. It is observed that the best result relates to the simulation in the month of April 2004, where the total rdmm reached values of 0.11 (URSI) and 0.09 (CCIR). Simulations for the months of October 2003 and January 2004 


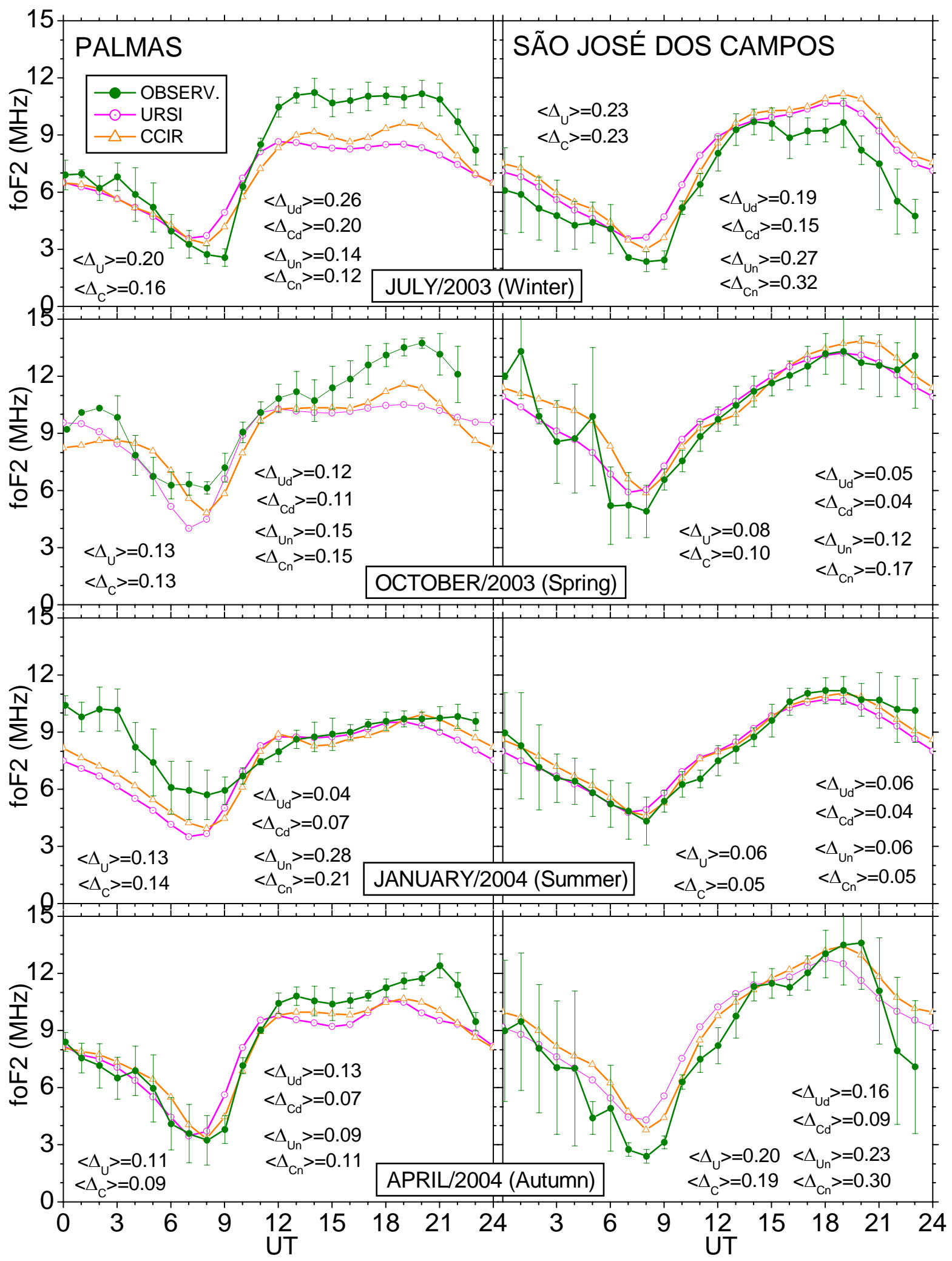

Fig. 1a. Plots of the observed average ionospheric parameter foF2 variations for different seasons at the Brazilian stations of Palmas and São José dos Campos. The IRI-2001 model curves, using both URSI and CCIR coefficients, for different seasons are also shown along, with the relative deviation module mean (rdmm), $\langle\Delta\rangle$, for URSI (U) and CCIR (C), as well as daytime (d) and nighttime (n) rdmms. 
(\%)

foF2 percent deviation

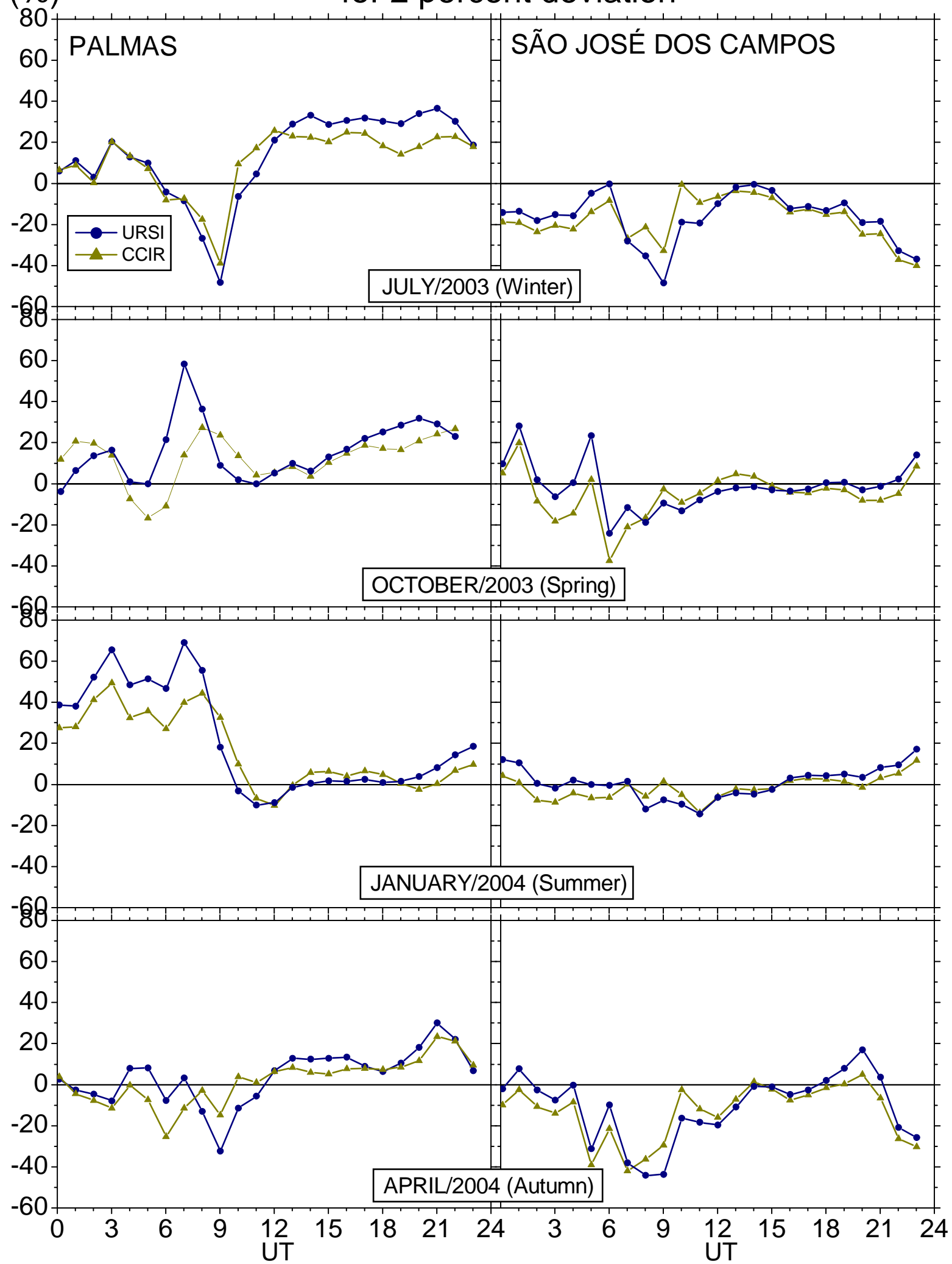

Fig. 1b. Plots of the percent deviation between the IRI (CCIR and URSI) model results and the observed values of the F-region critical frequency (foF2) as a function of time of the day and season at the stations PAL (left-hand side panels) and SJC (right-hand side panels). 
have practically the same results viz. 0.13 for either URSI or CCIR. Simulations for the month of July 2003 have total rdmm of 0.20 (URSI) and 0.16 (CCIR). Regarding the daytime/nighttime rdmms, the best agreement occurred for the month of January 2004, where the daytime rdmm reached 0.04 (URSI) and 0.09 (CCIR), however, the nighttime rdmm for that month exhibit higher values, indicating a disagreement between the observed and modeled curves. The occurrence of Spread-F, during October 2003, contaminated the measured foF2, between 23:00 and 03:00 UT.

Figure $1 \mathrm{~b}$ shows the percent deviation between the IRI (CCIR and URSI) model results and the observed values of the F-region critical frequency (foF2), as a function of time of day and season at the stations PAL (left-hand side panels) and SJC (right-hand side panels), according to the following equation:

$\sigma_{\mathrm{rel}}=\frac{x_{i}^{o}-x_{i}^{m}}{x_{i}^{m}} \times 100$,

where $x_{i}^{o}$ and $x_{i}^{m}$ represent the observed and modeled values, respectively. Regarding the results for the station PAL, one can notice positive differences (the model underestimates the foF 2 values) along almost the whole $24 \mathrm{~h}$ for the months of October 2003 and January 2004. For the months of July 2003 and April 2004, besides the positive differences (the model underestimates the foF2 values) mainly between 12:00 and 24:00 UT, negative differences (the model overestimates the foF2 values) between 06:00 and 10:00 UT (July) and between 00:00 and 12:00 UT (April) are observed. For the station SJC, negative differences for almost the whole $24 \mathrm{~h}$ can be observed for the months of July 2003 and April 2004. The best results are achieved for the month of January 2004 and October 2003. Comparing the results for these two stations, the models provide better results for SJC.

It should be mentioned that Batista and Abdu (2004), in a similar comparative study between the observed and IRI modeled ionospheric parameters, pointed out that, for a high solar activity period, there is a good agreement between the IRI predictions and observed mean foF2, for the Brazilian equatorial station of São Luís $\left(2.6^{\circ} \mathrm{S}, 44.2^{\circ} \mathrm{W}\right.$, dip $\left.-0.5^{\circ}\right)$, during the daytime. However, the authors pointed out that the F-layer critical frequency (foF2) after sunset is overestimated for the equatorial station São Luís. Our results generally show that the parameter foF2 is underestimated, during the daytime and nighttime, for the station PAL, which is not so close to the magnetic equator as São Luís.

Bittencourt and Chryssafidis (1994) also carried out comparative studies between the CCIR IRI predictions and observed data. The authors pointed out that the observed Fregion peak electron densities, at the low-latitude station of Fortaleza $\left(3.8^{\circ} \mathrm{S}, 38^{\circ} \mathrm{W}\right.$, dip $\left.-12^{\circ}\right)$, were higher than those predicted by CCIR IRI, during the representative winter and spring months (June and September, respectively), for high solar activity. Regarding the comparison of the observations at PAL, CCIR and URSI IRI-2001 predictions usually underestimate the foF2 values, during most of the day, generally from 10:00 to 24:00 UT.

Figure 1a shows that observed data, and the CCIR and URSI IRI-2001 predicted values of foF2 are quite reasonable for SJC, compared to PAL, for the months of October 2003 and January 2004, Southern Hemisphere spring and summer periods, respectively, since the daily rdmm has values of 0.10 (CCIR) and 0.08 (URSI) for spring, and 0.05 (CCIR) and 0.06 (URSI) for summer. The IRI-2001 predictions show less agreement with the observed values of foF 2 for the months of July 2003 and April 2004. The agreement is slightly better in April 2004 (0.19 (CCIR)) and (0.20 (URSI)) than July 2003 (0.23 for both CCIR and URSI). Also, it is observed that the results of the model have better agreement during the daytime for all the months. The best agreement between the observed and predicted values, during either the daytime or nighttime, is for the month of January 2004. It is interesting to note that, although the model curves sometimes, depart from the observed averaged curves, they usually lie within the standard deviation bars. In other words, this is a good indication that the CCIR and URSI IRI-2001 models generate data within the characteristic variability of the F-region over the location of SJC.

Batista and Abdu (2004) show that, for the station Cachoeira Paulista (near the equatorial ionization anomaly crest, like SJC), the parameter foF2 is generally in good agreement. Our results present the same trends for the station SJC, which is near Cachoeira Paulista. In addition, Batista and Abdu (2004) show that IRI/URSI overestimates the values of foF2 compared to the measurements, around $9 \mathrm{UT}$, during the months of April and July.

Figures $1 \mathrm{a}$ and $\mathrm{b}$ also show that the CCIR and URSI IRI2001 modeled curves exhibit a reasonable agreement between them. CCIR has some advantage over URSI for both locations, since the CCIR rdmm values are lower than those presented by URSI.

We have applied the POLAN ionogram inversion technique (Titheridge, 1985), in order to obtain $\mathrm{hmF} 2$ values for the days selected from PAL and SJC. In the present study, POLAN was run under the software UDIDA (Fagundes et al., 2005), to obtain the true height electron density profiles by conveniently choosing points in the ionograms. The profiles were calculated on an hourly basis. Figure $2 \mathrm{a}$ shows the plots of hmF2 values simulated by IRI-2001 and derived from POLAN. The PAL hmF2 data are on the left side and SJC hmF2 data on the right side. Only the CCIR numerical map provides values of $\mathrm{hmF} 2$. Using the same criterion of the rdmm as mentioned earlier, it is noted that in five out of eight simulations presented, the observed $\mathrm{hmF} 2$ values exhibit $\langle\Delta\rangle$ equal to or less than 0.06 , which is indicative of a good agreement between the observed and modeled values. However, it is necessary to highlight some additional points. Comparisons at PAL exhibit a good agreement for the seasons represented by the months of July 2003, January and 
April 2004. April 2004 shows the best comparative results for that parameter. In terms of daytime/nighttime rdmm, two simulations have better results for daytime (October 2003 and April 2004) and two for nighttime (July 2003 and January 2004). In other words, PAL daytime simulations exhibited better results for both the autumn and spring seasons, and nighttime simulations for the winter and summer. The pre-reversal peak of the vertical ionospheric drift, near the magnetic equator, which is directly evidenced by the $\mathrm{hmF} 2$ increase (Fig. 2a), usually around 21:00 UT, is not well simulated by IRI-2001. In other words, CCIR IRI-2001, in the equatorial ionospheric region, around the sunset hours, underestimates hmF2. Regarding the SJC modeling results, CCIR IRI-2001 provided good simulations for July and October 2003, according to rdmm criterion, although visual analysis points out that the best result was reached for the latter month. SJC daytime simulations have presented better results than the nighttime simulations for the three seasons represented by the months October 2003, January and April 2004. Comparing PAL and SJC IRI-2001 simulations of the $\mathrm{hmF} 2$ parameter, two of them are better for PAL (January and April 2004) and two are better for SJC (July and October 2003). Figure $2 \mathrm{a}$ also shows that, around sunrise hours, there is another increase in the $\mathrm{hmF} 2$ values that is not reproduced by IRI-2001, either at PAL or SJC. In addition, from 00:00 to 04:00 UT, CCIR IRI-2001 usually overestimates hmF2 for both locations.

Figure $2 \mathrm{~b}$ shows the percent deviation between the IRI (CCIR) model results and the calculated values of the Fregion peak height (hmF2) as a function of time of day and season at the stations PAL (left-hand side panels) and SJC (right-hand side panels), according to Eq. (2). It should be mentioned, once more, that only the CCIR numerical map provides values of $\mathrm{hmF} 2$. It is noticed that the $\mathrm{hmF} 2 \mathrm{sim}-$ ulations for both stations exhibit less percent deviation than the foF 2 simulations. Apparently, there is a trend of positive differences (the model underestimates the hmF2 values) between roughly 03:00 and 12:00 UT for the two stations in all seasons, and the underestimation persists for the station PAL around sunset hours for the months of October 2003, January and April 2004.

Abdu et al. (1996) presented, among other results, a comparison between monthly averaged $\mathrm{hpF} 2$ values for MarchApril (autumn) of the years 1991 and 1992 (high to moderate solar activity) for the low-latitude station Fortaleza $\left(4^{\circ} \mathrm{S}\right.$, $38^{\circ} \mathrm{W}$, dip $-12^{\circ}$ ), which is comparable in magnetic latitude to the station PAL. The ionospheric parameter hpF2 is obtained from ionograms and is an estimate of the true height of the F-layer density peak. The authors pointed out that IRI-90 did not adequately reproduce the F-layer height near sunset. So, the comparisons presented in Figs. 2a and b (this work) corroborate the same trends pointed out by Abdu et al. (1996).

Batista and Abdu (2004) showed that the F-layer peak height in the evening is underestimated by IRI for the equa- torial station São Luís $\left(2.6^{\circ} \mathrm{S}, 44.2^{\circ} \mathrm{W}\right)$. Once more, our results reinforce this same characteristic.

Observing the foF2 behavior pattern at those two locations, one can infer the equatorial anomaly ionization (EIA) behavior, as well, since foF 2 is directly proportional to the maximum electron density of the ionospheric plasma. Figure 3 shows the observed average variations of foF 2 values at PAL and SJC, together with the CCIR and URSI IRI-2001 simulations for the different seasons. It is noticed that the observed foF2 values are higher for PAL than for SJC, during almost the whole $24 \mathrm{~h}$ in July 2003 . The CCIR and URSI IRI-2001 models do not predict such behavior. It is probably related to the pattern of the magnetic meridional winds over those locations, which causes the well-known asymmetry of the EIA. As a result, the ionization over Palmas (closer to the EIA trough) is denser than that predicted by the models. In October 2003 (spring), between 13:00 and 19:00 UT, no significant difference between ionization over those two locations is observed, and it is noticeable that the CCIR and URSI IRI-2001 simulations have underestimated the foF2 values for PAL, apparently due to the same characteristic asymmetry caused by the magnetic meridional wind patterns. In January 2004, the best results for the simulation of the EIA are observed between 13:00 and 21:00 UT. Finally, in April 2004, the EIA is also well simulated, although with a lower agreement compared to the simulation in January 2004; the ionospheric parameter foF2 was underestimated for PAL, between 11:00 and 24:00 UT.

Earlier papers by Lyon et al. (1963) and Shastri et al. (1996) suggest that there is a differential shift of the EIA crests with solar activity for different seasons in different longitude sectors. Shastri et al. (1996) have presented comparison between the observed data and predictions of the IRI-90 in the Indian sector. In this work, we have presented comparative studies of the seasonal and latitudinal variations between the observed data at two stations in the Brazilian sector and the predictions by the CCIR and URSI IRI-2001 models. Our results point out that the model overestimates the EIA trough in the Brazilian sector, that is, it underestimates the ionospheric parameter foF 2 for the station PAL. The present study suggests that the CCIR and URSI IRI-2001 models should be improved for predictions for the EIA shape in the Brazilian longitude sector.

\section{Conclusions}

Comparative studies presented in this work showed that the IRI-2001 model provided data with different degrees of agreement relative to the digital ionosonde observed data, depending on the location. Analyses were carried out in two ways: visually and quantitatively. The latter consists of applying a criterion called "relative deviation module mean" (rdmm) (Bertoni, 2004). We have selected five magnetically quiet days in the months of July 2003, October 2003, January 


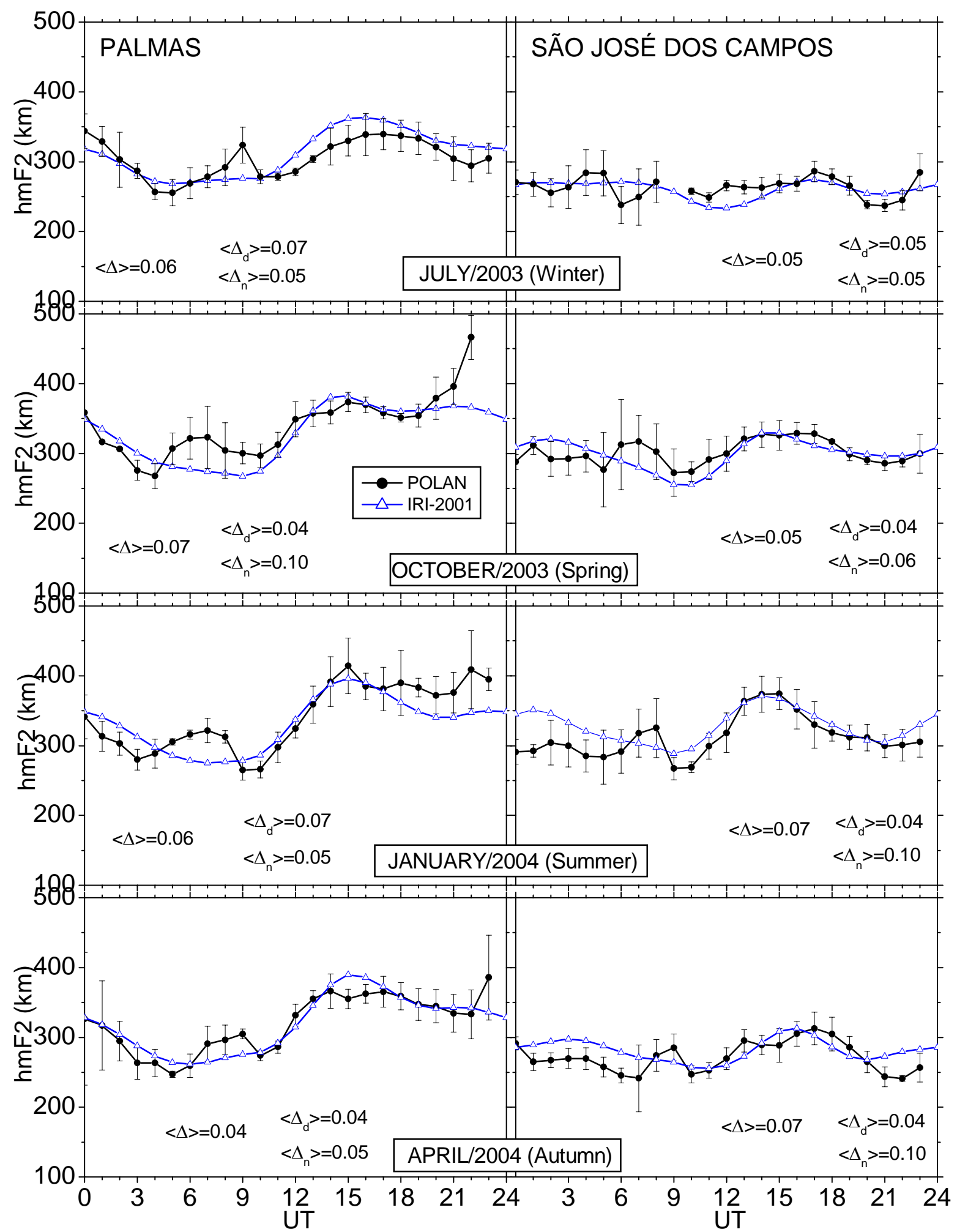

Fig. 2a. Plots of the average ionospheric parameter hmF2 for different seasons derived from POLAN using observations at Palmas and São José dos Campos with hmF2 obtained from the IRI-2001 model for these two stations. Also, the relative deviation module mean (rdmm), $\langle\Delta\rangle$ : daytime (d) and nighttime (n) are presented. 
(\%)

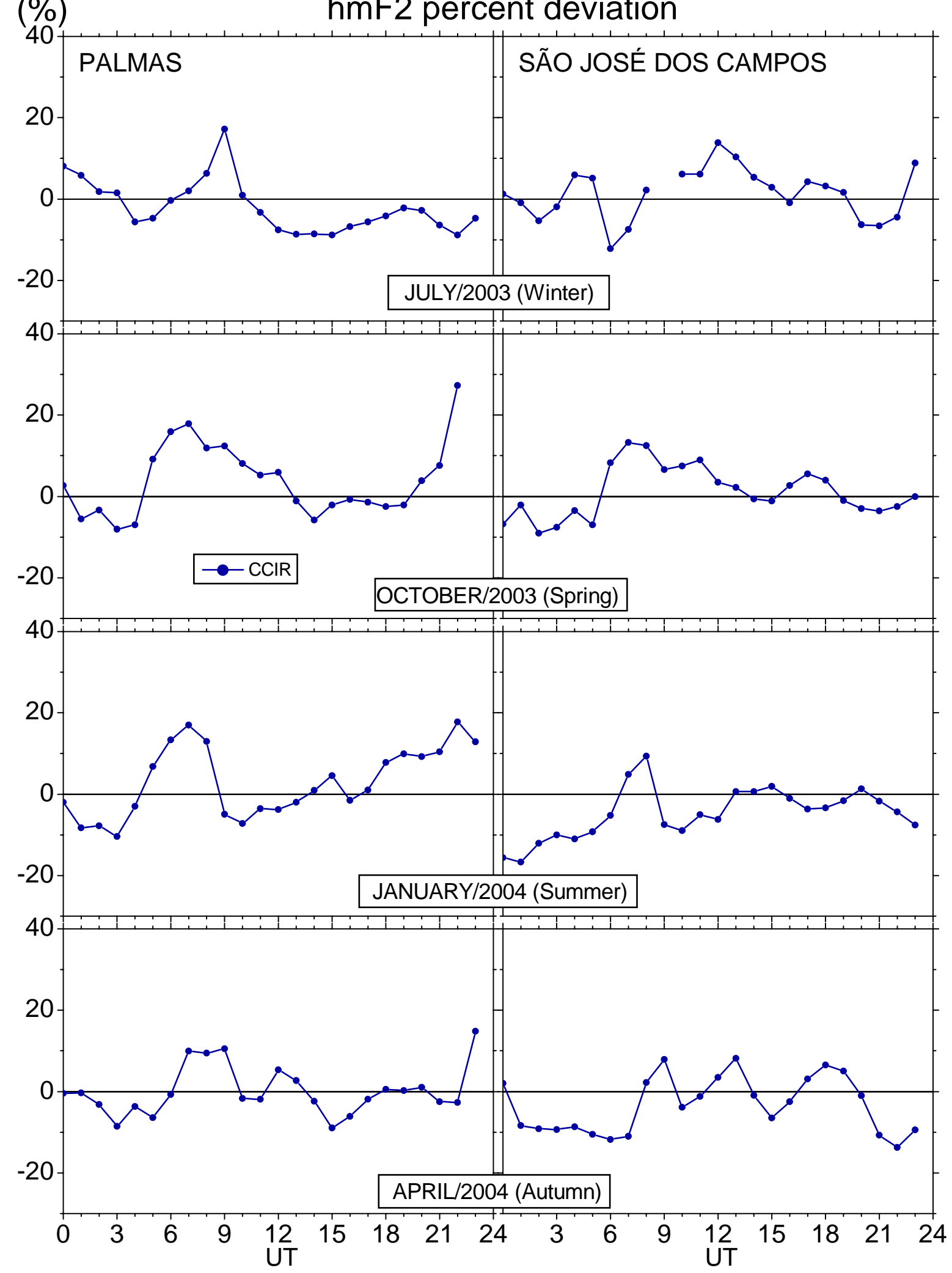

Fig. 2b. Plots of the percent deviation between the IRI (CCIR) model results and the calculated values of the F-region peak height (hmF2) as a function of time of day and season at the stations PAL (left-hand side panels) and SJC (right-hand side panels). 


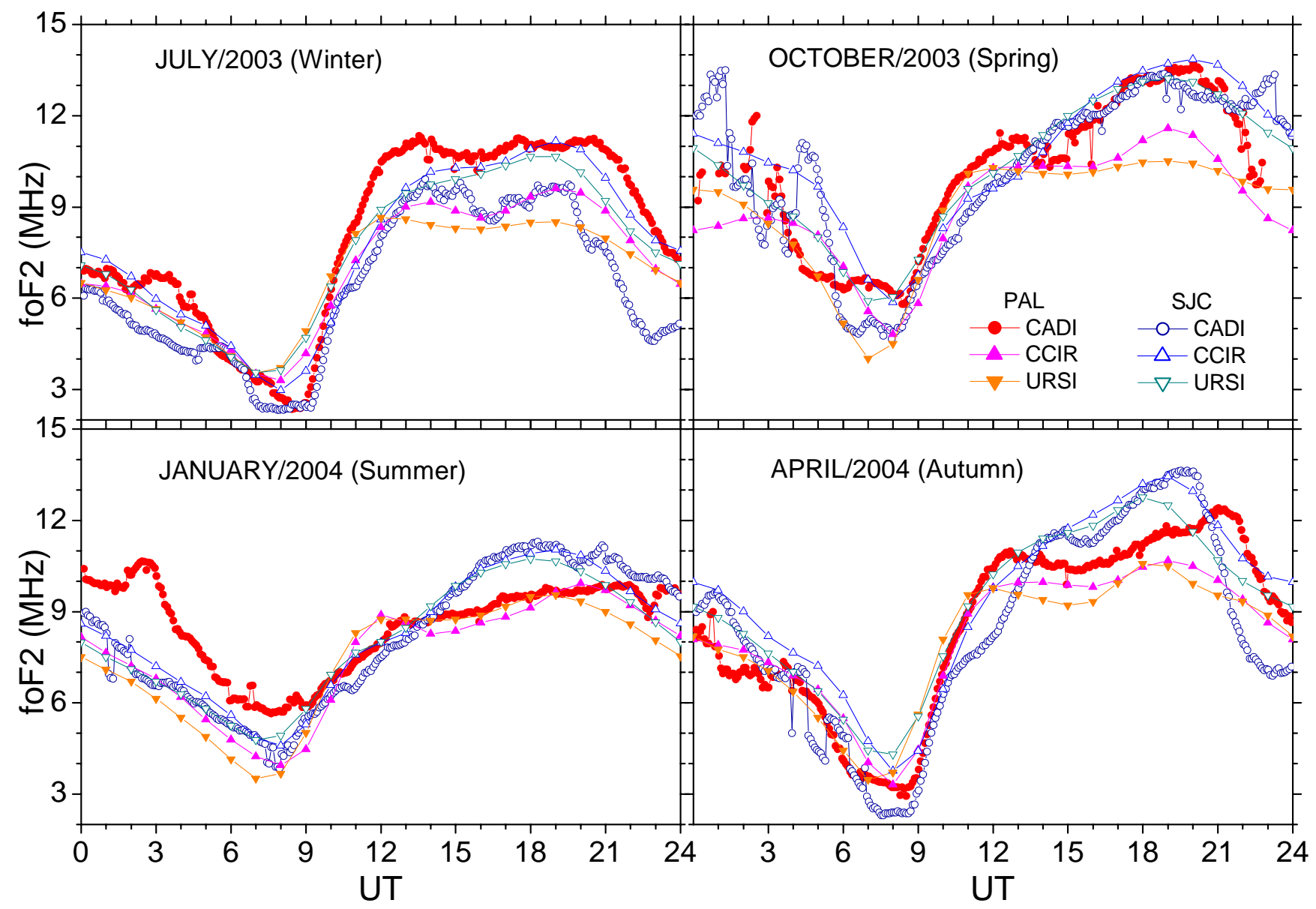

Fig. 3. Plots of the average observed ionospheric parameter foF2, measured at the Brazilian stations of Palmas and São José dos Campos, by digital ionosondes type Canadian Advanced Digital Ionosonde (CADI), at five-minute intervals, during the months of July and October 2003, January and April 2004 (representing different seasons). Also, the IRI-2001 simulations are superposed.

2004 and April 2004 as representatives of the winter, spring, summer and autumn seasons, respectively, according to the availability of the observational data at the two stations. Solar activity during the periods was high to moderate.

Regarding the low-latitude station Palmas (PAL), the CCIR and URSI IRI-2001 models presented reasonable to poor simulations of the ionospheric parameter foF 2 by either visual analysis or rdmm criterion. The visual analysis reveals that the models usually underestimate this parameter, for all the seasons represented by different months in the time interval of 10:00 to 24:00 UT. The rdmms exhibited values higher than 0.06 , reinforcing the reasonable to poor agreement between the modeled and observed curves. The best result was obtained for January 2004 (summer), during the daytime (09:00 to 20:00 UT).

On the other hand, the IRI-2001 model provides reasonable to good values for foF2 for the station São José dos Campos (SJC), during most of the $24 \mathrm{~h}$ and for all the seasons. Either visually or through the results of rdmm, the
CCIR and URSI IRI-2001 models provided good results for October 2003, and January 2004, and reasonable results for July 2003 (winter) and April 2004 (autumn). Usually predicted values lie within the deviation bars, indicating that the IRI-2001 model generates data within the characteristic variability of the F-region over the location of SJC.

CCIR and URSI IRI-2001 models generated similar results, since there is reasonable agreement between their curves. However, CCIR model results are a little better compared with URSI model for SJC.

True height profiles derived by POLAN (Titheridge, 1985), running under the software UDIDA (Fagundes et al., 2005), provided values of the ionospheric parameter hmF2. Comparisons carried out in this work suggest that in general, the CCIR IRI-2001 model simulates very reasonably hmF2, for both locations. Simulations during the daytime exhibit better results for the station SJC.

The ionospheric parameter foF 2 is directly related to the maximum electron density of the ionospheric plasma. Since 
this parameter was generally underestimated by the CCIR and URSI IRI-2001 simulations compared to the observed data, for the station Palmas, and generally was in good agreement with the observed data for the station São José dos Campos, the models apparently did not reproduce adequately the EIA shape over the Brazilian sector, as they should provide higher foF2 values for the low-latitude station Palmas in the representative months of July 2003 (winter), October 2003 (spring) and April 2004 (autumn), between 10:00 and 24:00 UT. Better results were achieved in the simulations for January 2004 (summer), between 13:00 and 21:00 UT (LT=UT-3 h).

Ionospheric measurements carried out at geomagnetic low-latitude stations around the world are important for the improvements in CCIR and URSI numerical maps, in order to obtain better and more realistic results for the modeling of such regions and for the characteristic ionospheric parameters given by the International Reference Ionosphere.

Acknowledgements. This work was supported by the Brazilian funding agency CNPq, DCT/SEPLAN-TO and CEULP/ULBRA under grant 350448/2004-3. Thanks are due to the Brazilian funding agencies $\mathrm{CNPq}$ and FAPESP for the partial financial support through grants: 301222/2003/7 (CNPq); 2004/10104-9 (FAPESP). Authors thank I. S. Batista for helpful discussions.

Topical Editor M. Pinnock thanks N. Balan and K. J. W. Lynn for their help in evaluating this paper.

\section{References}

Abdu, M. A., Batista, I. S, and de Souza, J. R.: An overview of IRI-observational data comparison in American (Brazilian) sector low latitude ionosphere, Adv. Space Res., 18, 13-22, 1996.

Batista, I. S. and Abdu, M. A.: Ionospheric variability at Brazilian low and equatorial latitudes: comparison between observations and IRI model, Adv. Space Res., 34, 1894-1900, 2004.

Batista, I. S., Abdu, M. A., de Medeiros, R. T., and de Paula, E. R.: Comparison between IRI predictions and digisonde measurements at low latitude station, Adv. Space Res., 18, 49-52, 1996.

Bertoni, F.: Derivas Ionosféricas em Latitudes Equatoriais: Observações e Modelagem, Ph.D. Thesis (available only in Portuguese Language), Instituto Nacional de Pesquisas Espaciais (INPE), São José dos Campos, Brazil, 2004.

Bilitza, D.: International Reference Ionosphere 2000, Radio Sci., 36, 261-275, 2001.

Bilitza, D., Sheikh, N. M., and Eyfrig, R.: A global model for the height of the F2-peak using M(3000)F2 values from the CCIR numerical map, Telecomm. J., 46, 549-553, 1979.
Bittencourt, J. A. and Chryssafidis, M.: On the IRI model predictions for the low-latitude ionosphere, J. Atmos. Terr. Phys., 56, 995-1009, 1994.

CCIR: Atlas of ionospheric characteristics, Comité Consultatif International des Radiocommunications, Report 340-6, Int. Telecommun. Union, Geneva, 1991.

CCIR: Atlas of Ionospheric Characteristics, Comité Consultatif International des Radiocommunications, Report 340-4, Int. Telecommun. Union, Geneva, 1967.

Fagundes, P. R., Pillat, V. G., Bolzan, M. J. A., Sahai, Y., BeckerGuedes, F., Abalde, J. R., Aranha S. L., and Bittencourt J. A.: Observations of F-layer electron density profiles modulated by planetary wave type oscillations in the equatorial ionospheric anomaly region, J. Geophys. Res., 110, A12302, 1-8, 2005.

Fox, M. W. and McNamara, L. F.: Improved World-Wide Maps of Monthly Median foF2, J. Atmos. Terr. Phys., 50, 1077-1086, 1988.

Grant, I. F., MacDougall, J. W., Ruohoniemi, J. M., Bristow, W. A., Sofko, G. J., Koehler, J. A., Danskin, D., and Andre, D.: Comparison of plasma flow velocities determined by the ionosonde Doppler drift technique, SuperDARN radars, and patch motion, Radio Sci., 30, 1537-1549, 1995.

Lyon, A. J. and Thomas, L.: The F2-region equatorial anomaly in the African, American and East Asian sectors during sunspot maximum, J. Atmos. Terr. Phys., 25(7), 373-386, 1963.

Rush, C.M., Fox, M., Bilitza, D., Davies, K., McNamara, L., Stewart, F., and PoKempner, M.: Ionospheric mapping: an update of foF2 coefficients, Telecomm. J., 56, 179-182, 1989.

Rush, C. M., PoKempner, M., Anderson, D. N., Perry, J. C., Stewart, F. G., and Reasoner, R.: Maps of foF2 Derived from Observations and Theoretical Data, Radio Sci. 19, 1083-1097, 1984.

Rush, C. M., PoKempner, M., Anderson, D. N., Stewart, F. G., and Perry, J.: Improving Ionospheric Maps Using Theoretically Derived Values of foF2, Radio Sci. 18, 95-107, 1983.

Sethi, N. K., Dabas, R. S., and Vohra, V. K.: Ddiurnal and seasonal variations of $\mathrm{HmF} 2$ deduced from digital ionosonde over New Delhi and its comparison with IRI 2001, Ann. Geophys., 22, 453-458, 2004, http://www.ann-geophys.net/22/453/2004/.

Shastri, S., Aggarwal, S., and Sethi, N. K.: Performance of IRI model predictions of F-region for Indian latitudes, Adv. Space Res., 18, 41-44, 1996.

Souza, J. R. de, Bailey, G. J., Abdu, M. A., and Batista, I. S.: Comparison of low latitude $F$ region peak densities, heights and equatorial ExB drift from IRI with observational data and the Sheffield University plasmasphere ionosphere model, Adv. Space Res., 31, 501-505, 2003.

Titheridge, J. E.: Ionogram analysis with the generalized program POLAN, Report UAG-93, World Data Center A for SolarTerrestrial Physics, U.S. Dept. of Commerce, Boulder CO, 80301 USA, 1985. 